\title{
A Space Operations Network Alternative: Using Globally Connected Research and Education Networks for Space-based Science Operations
}

\author{
Robert N. Bradford ${ }^{1}$ \\ NASA/Marshall Space Flight Center, Huntsville, Alabama, 35812, USA
}

\begin{abstract}
I. Abstract
In this paper we investigate the feasibility of using Research and Education Networks in support of spacebased science operations. To determine the feasibility we first briefly describe these networks and then compare the performance of the U.S. REN the Abilene Network against the NASA Integrated Services Network's (NISN) published performance specifications. To further demonstrate feasibility we describe how the International Space Station is currently using Abilene in its space-based science operations. We also describe how the Solar B Satellite to be launched this September is planning on using the international RENs to distribute its science data. In conclusion, RENs provide a more than adequate network service to support space-based science operations.
\end{abstract}

\section{Introduction}

$\mathrm{W}$ hat is not common knowledge in the space based science community is the existence of the worldwide Research and Education Network (REN) and what benefits RENs can bring to this community. In this paper we will briefly describe what RENs are, their connectivity, underlying architecture, the services they provide and how they can benefit space based science. For anyone who wants to investigate RENs further to and from specific end points go to http://www.internet2.org. From this link, a vast amount of information is available. To compare the level of services provided by RENs (in this case the Abilene network), we will compare the network performance specifications of the NASA Integrated Services Network (NISN) and the Abilene Network. The NISN is NASA's network that provides all mission network support ranging from launches to scientific operations. Abilene is the USA's REN. It must be emphasized that the use of RENs in manned flight is not recommended at this point except in manned flight science operations as it is today. To demonstrate these benefits we will briefly describe how the International Space Station (ISS) uses the Abilene network in its science operations and how the Japanese Solar B satellite project is planning on using RENs quite extensively in its science operations and the benefits being derived. An objective throughout this paper is to provide adequate information for other projects to at least investigate using RENs in their science operations.

For adequate science to take place, scientists must be able to access the data from their home base at a university or scientific institute etc. Connectivity and network performance is critical at a cost that does not take away from the science being supported. In other words, if connectivity costs so much that scientific collaboration either doesn't happen nor has a high associated cost, then clearly science looses. If data access is provided by other out dated means e.g. sending tapes or CDs which has its own unique costs, not to mention their obvious inefficiencies, science again looses. A major objective of this paper is to inform the space based scientific community of the existence of RENs and their potential benefits.

\section{REN Background}

Research and Education Networks were conceived prior to the Internet as a DARPA project. Actually the Internet as we know it today was originally formed to support the scientific community. The networking infrastructure was "taken over" as the benefits of what we now know as the Internet became clear. The first USA REN was the very high Broadband Network Service (vBNS) established in the early 90 's by the National Science Foundation. It was eventually replaced by the Abilene Network that is the current USA REN. The evolution of network technology has caused a growth explosion in RENs worldwide. Now the world is connected via RENs which defies explanation. The only continent not readily connected is Africa and even this is changing. Within most countries there exists a national REN. These national RENs provide connectivity to colleges, universities, science centers, institutes and governmental agencies within a country. The GEANT, APAN and AMPATH

${ }^{1}$ Manager, Mission Operations Laboratory, Mail Code: EO40 
organizations provides intercontinental connectivity between the US and Europe, Asia and Oceania and the Caribbean, South/Latin America respectively. These are the connector links traversing continents and oceans.

One of the problems in space based science is getting the science (data) from the source, a satellite, to a satellite receiving station, processed at a science center and out to the science community at a university or institute and on to other locations for possible scientific collaboration. A break in this line, generally due to cost, negates effective collaboration especially internationally. If a scientist must wait long periods of time to get access (via tapes or CDs), or the data is corrupted and must be resent again, then scientific collaboration starts to break down. Today very large data sets are being created that require high bandwidth networks.

To illustrate how a space based scientific endeavor can benefit from RENs we will describe how the International Space Station uses Abilene for on board scientific operations and how the Solar B Satellite Project will use RENs when it is launched.

\section{Discussion of Research and Education Networks}

In this section we will attempt to educate the reader on the very basics of RENs. This section is not all inclusive and we encourage the reader to visit the individual web sites associated with a specific country's network connectivity. Of significant importance is the lack of nationalism associated with RENs. There is a sense of duty that seems to preclude nationalistic tendencies where the networks come first. This is an empirical observance by the author not founded by any research. RENs are publicly funded networks through government funding, corporate support and membership fees.

\section{A. Purpose}

The purpose of RENs is straight forward. They exist to provide network connectivity for research and educational purposes. They do not support the commodity Internet. Research covers a range from network research to discipline specific scientific research. Education covers all aspects of education, including access to information, streaming video, collaborations and online teaching. Ancillary support is generally allowed that is related to commodity Internet traffic e.g. VoIP, access to the Internet for research purposes and email.

\section{B. REN Organization}

Each international region and individual nations have their own network organization infrastructure. The Asian Pacific Advanced Network and GEANT are examples. For network specific discussions in this paper because RENs are so prevalent, we will discuss in more detail the USA's Abilene REN. The Abilene network is supported by the University Corporation for Advanced Internet Development (UCAID) under Internet2, a consortium of over 205 nationally recognized colleges and universities. UCAID is a private non profit corporation that provides the oversight, funding and management for the Abilene network. Funding is provided from many sources. Schools and other organizations must join and pay dues to connect to Abilene. Grants and research funding comes from the National Science Foundation which is a funding source for Abilene. The last major funding sources are the sponsoring commercial networking and governmental science organizations.

There is no worldwide recognized REN control authority. The Internet2 does provide a global centralized network operations center for international networks and connectors. The Global NOC is located at the Indiana University/Purdue University campus at Indianapolis (IU/PUI). This Global NOC however does not provide service within a national network and does not have insight into internal operations.

\section{Condition of Use (CoU) Policies}

Most, if not all, RENs have a condition of use policy. The overall policies concerning use of RENs are different depending on region and national locations but generally the use must be related to scientific and network research and education. Membership restrictions vary between national and international entities. However, when traversing other networks to get to a far away end point, whether traversing it or delivering to it, it is not required that memberships to all networks, in between end points, is required. Once membership is accepted by one entity, it is generally recognized by all other RENs including connectors.

The Abilene Network states: "As a project of Internet2, the Abilene network has established Conditions of Use $(\mathrm{CoU})$ that seek to advance the Internet2 project's goal of encouraging and enabling the development of advanced network applications. Abilene provides high-performance networking for data traffic among participating gigaPoPs and Regular Members, as well as other organizations whose connectivity benefits higher education in the United 
States. Abilene traffic primarily and clearly serves the teaching, learning, research, and clinical missions of US higher education, plus related support infrastructure, services, and content. Abilene does not seek to compete with the commodity Internet or other telecommunications services, and is not intended to carry any commercial traffic unrelated to Internet2 goals, or any traffic with proprietary, classified, or illegal purposes. All Abilene participants agree to comply with conditions and charges set by Internet2 for using the Abilene network."2

As stated in the Abilene's CofU, scientific data including scientific space based operations is included. The International Space Station remote scientist uses Abilene to conduct all ISS science including commanding of experiments, receipt of telemetry, voice and streaming video.

\section{Current Services Provided b y RENs}

The span of network technology advancement within RENs is very location dependent. Network infrastructure varies greatly. The installed infrastructure of the Abilene network and its connection points are all based on advanced fiber technologies. It is not uncommon to see T1s and T3s in some of the more remote locations of the world. The typical services provided are network operations center support for operations, IPv6, multicast and quality to service (QoS). Abilene offers a redundancy service at their connection points which eliminates single points of failure and increases reliability. These technologies are implemented at varying degrees worldwide.

\section{E. A Brief Connectivity Overview}

The Abilene REN architecture consists of high speed fiber optics, routers with a significant ability to reroute when failures do occur, peering and gigaPoPs between Abilene and regional networks. Figure 1 depicts the topology of the Abilene Network. The network is comprised of rings that provides significant redundancy and high reliability. During hurricane Katrina the link between Atlanta and Houston which runs through New Orleans was disabled. Even though the failure was catastrophic, no reduction in service was encountered by users. The service was restored 9.5 days after the storm. There is no location on the network that is not serviced by at least two different links. In the event of one link going down the traffic is immediately rerouted on the other link to maintain service. As Table 2 indicates sufficient bandwidth exists on all links to handle this type of rerouting.

Due to the vast interconnectivity between the International RENs they act as one very large ring based network worldwide. The international REN literally traverses the world, and goes as follows: starting at the StarLight connector in Chicago, to the Asia Pacific Advanced Network to Japan, to Gloriad across Russia, to Europe, where it connects with GEANT across the Atlantic back to StarLight. Although this description sounds like a single circuit this connectivity is made up of multiple $10 \mathrm{Gbps}$ fiber optic circuits, connector points and national RENs. A break in any one of these circuits does not materially affect overall service.

Shown in Figures 2 and 3 below is the logical view of the Abilene network showing the connecting regional and state RENs and international RENs, respectively, and shows how extensive the connectivity is between end points. What is not shown is the vast connectivity at the local level within a state ending in classrooms and labs. There are 36 Abilene Connectors located nationwide.

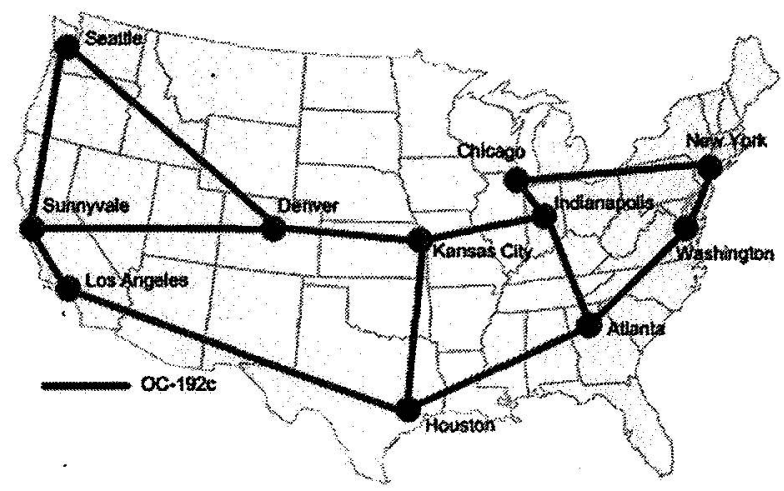

Figure 1, the Abilene Network Backbone ${ }^{3}$

\footnotetext{
${ }^{2}$ [1] abilene.internet2.edu/policies/cou.html

${ }^{3}[1]$ abilene.internet2.edu/maps-lists/
} 


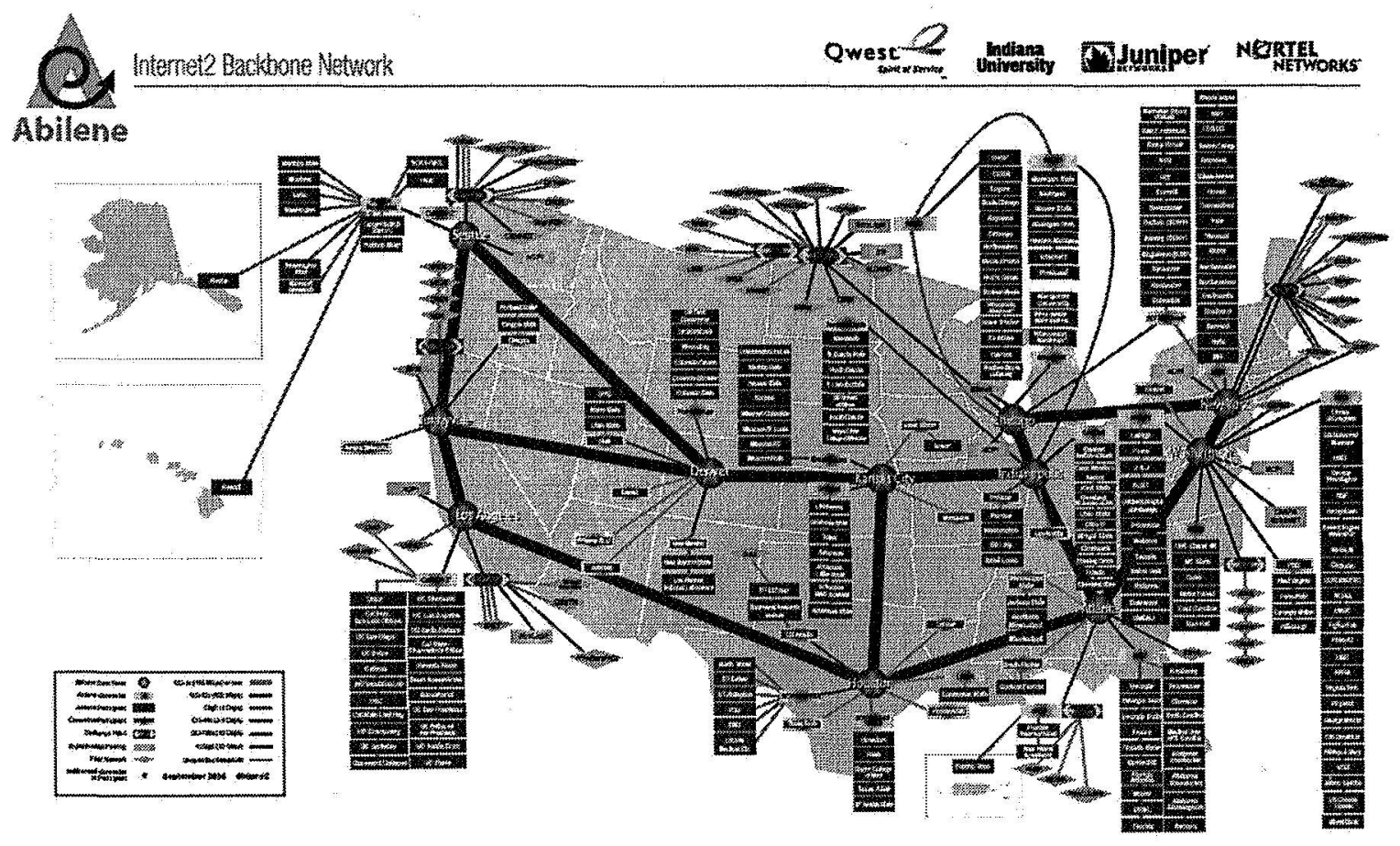

Figure 2, the Abilene Network Logical Map ${ }^{4}$

\section{Abilene International Network Peers}

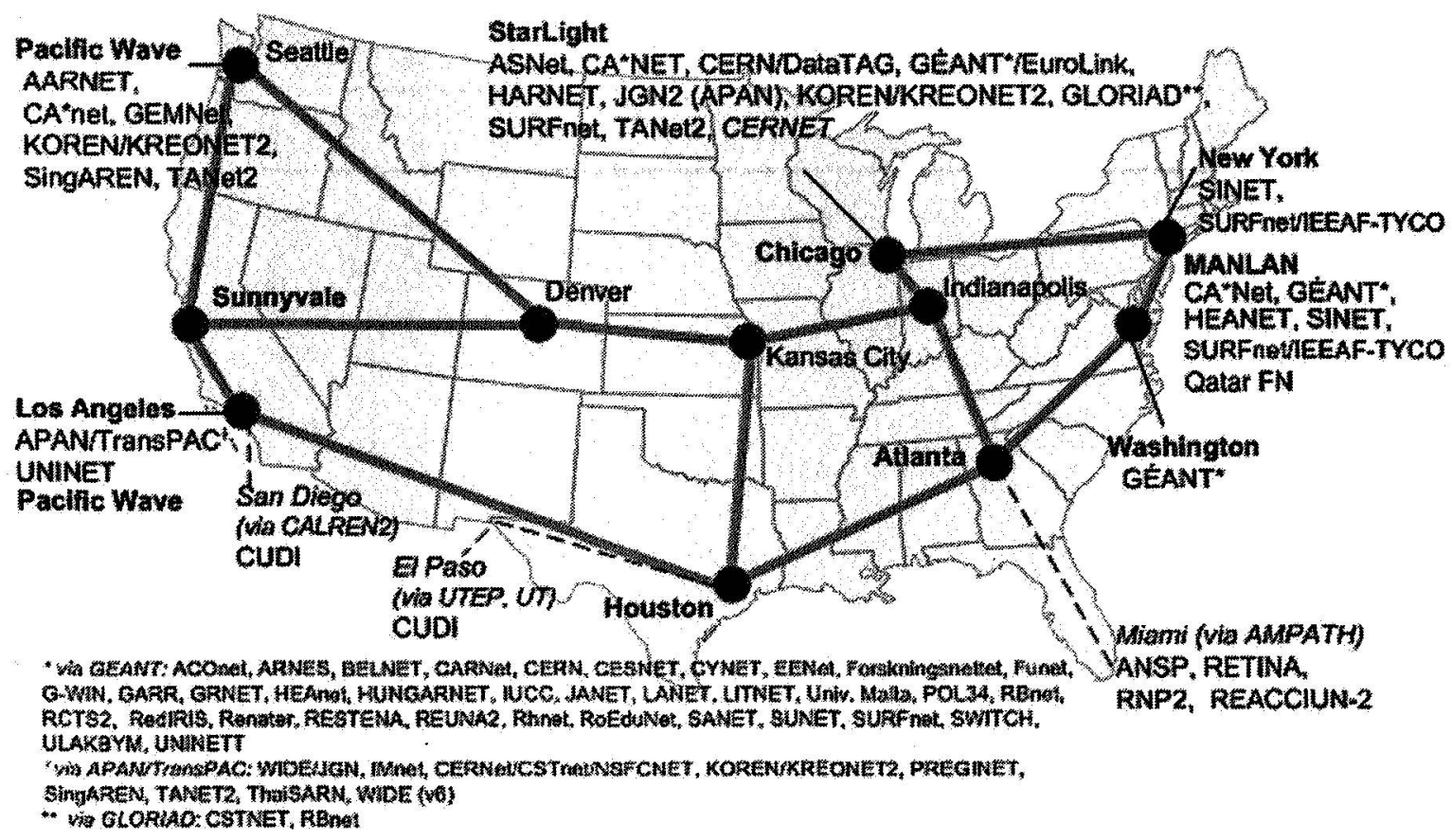

${ }^{4}$ [1] abilene.internet2.edu/files/abilene-logical-map.pdf 


\section{Figure 3, the Abilene Network Connector Networks ${ }^{5}$}

\section{F. Peering Relationships and Connectors}

What makes the REN networks so powerful is the connectors which link them together at the state, regional, national and international levels. The connectors to Abilene in Figure 3 shows the Abilene connectors, where an OC3 is $155 \mathrm{Mbps}, \mathrm{OC} 12$ is $622 \mathrm{Mbps}$, OC 48 is $2.4 \mathrm{Gbps}$ and OC192 is 10Gbps. These types of connectors are typical in the industrialized world and many up and coming nations worldwide. What make the worldwide REN so robust are the peering relationships between regional and national RENs and these relationships with trans oceanic networks like TransPAC for APAN.

Almost without exception networks have peering relationships with multiple networks and multiple peering locations with the same network. For example, between Abilene and the NASA Integrated Services Network (NISN) there are three different peering locations, one on the west coast, one on the east coast and one in Chicago. These multiple peering locations will avoid single points of failure since a peering relationship equates to a physical location.

A peering relationship is an agreement between two networks to transfer traffic between themselves and to provide a physical place to accomplish this transfer. These peering locations are called various things like GigaPOPS, connectors and possess specific names like Pacific Wave and StarLight. For the USA there are major peering locations in New York City, Miami, Chicago, Seatle and Los Angeles. Their location somewhat dictates the emphasis of their connection points e.g. East coast to Europe, West coast to Asia and Oceania and Southern Gulf Coast to the Caribbean, Latin and South America. Without peering relationships there would be no RENs or for that matter no Internet.

\section{G. Specific Network Operational Specifications for Space Operations}

For space based satellite operations, NASA uses the NISN to provide all network services. NISN has four levels of service. They are SIP, PIP, Mission Critical and Real-time Mission Critical. The following is a brief description of each service. Table 1 provides the performance specifications for each service taken from the NISN Services Document.

"RT Mission Critical: This service provides a real-time critical level of data networking connectivity with emphasis on meeting real-time telemetry transport using the Internet Protocol suite. Real-time Critical IP (RCIP) service is primarily differentiated from Mission Critical IP (MCIP) service in that it is engineered with a higher level of redundancy to achieve the added level of availability. This service employs the same security and connectivity features and limitations as the Mission Critical service. It is used to support life and vehicle threatening activities where no disruption of network service can be tolerated and delivery is in real-time less the laws of physics.

Mission Critical: This service provides a mission critical level of data networking connectivity using the IP suite with controlled access and security measures. MCIP service is differentiated from Standard IP (SIP) service in that it is engineered as a closed system to support space flight mission critical telemetry and data flows. All systems and facilities connected to the MCIP service shall meet the specified IT security level. Access to and from the general Internet and other NASA IP services is extremely limited and provided on a strictly managed "by exception" basis. MCIP service is most appropriate for critical space flight mission support data and telemetry flows that require (1) an extremely high level of availability for mission success and (2) no general Internet access.

PIP: This service provides a premium level of data networking connectivity using the IP suite. Premium IP (PIP) service is differentiated from SIP service in that it provides a higher performance level, higher priority for problem resolution, and is not directly connected to the general Internet. PIP connectivity to the general Internet is through a controlled gateway and is implemented on an exception basis only. PIP service is most appropriate for internal Agency networking requirements where the Agency's operations should be isolated from the general Internet. PIP service is not used in space flight operations. It is used in space flight science operations for ISS.

SIP: This service provides for basic data networking connectivity using the IP suite. SIP service is the commodity Internet service that provides the Agency's link to the Internet in general. It provides basic universal Internet connectivity with minimal performance guarantees or restrictions on acceptable use. SIP service is open to the public to enable access to publicly available NASA information sources such as World Wide Web services."

\footnotetext{
${ }^{5}$ [1] abilene.internet2.edu/maps-lists/

${ }^{6}$ [2] NISN Services Document, April 2005 http://nisn.msfc.nasa.gov/DocumentPages/Services.html
} 
1. Mission Critical Networks (NISN Provided)

The following table provides the specification for each service level as published by NISN:

\begin{tabular}{|l|c|c|c|c|c|}
\hline \multicolumn{1}{|c|}{$\begin{array}{c}\text { Service } \\
\text { Category }\end{array}$} & $\begin{array}{c}\text { Availability } \\
\text { (Percent) }\end{array}$ & $\begin{array}{c}\text { Restoral } \\
\text { Time }\end{array}$ & Coverage Period & $\begin{array}{c}\text { Acceptable Packet } \\
\text { Loss } \\
\text { (Percent) }\end{array}$ & Round Trip Time $^{5}$ \\
\hline Real-time Critical & 99.98 & $<1 \mathrm{~min}^{1}$ & $24 \times 7$ & 0.001 & $<120 \mathrm{~ms}$ \\
\hline Mission Critical & 99.95 & $2 \mathrm{hr}^{2}$ & $24 \mathrm{X} 7$ & 0.001 & $<120 \mathrm{~ms}$ \\
\hline Premium & 99.50 & $4 \mathrm{hr}^{2}$ & $24 X 7$ & $<1.0$ & $<100 \mathrm{~ms}$ \\
\hline Standard & 99.50 & $<24 \mathrm{hr}^{2,3}$ & $\begin{array}{c}\text { 6 a.m. Eastern Monday to } \\
6 \text { p.m. Pacific, Friday }\end{array}$ & 1.0 & $<250 \mathrm{~ms}$ \\
\hline
\end{tabular}

Table 1, the NASA Integrated Services Network (NISN) Internet Protocol Performance Specifications ${ }^{7}$

Note 1: A capability for immediately switching to an alternate data path shall exist.

Note 2: These restoral times represent the time to restore service to the user and assume immediate access to the user's facility to repair/replace equipment if necessary.

Note 3: The 24-hour restoral time results from the decreased priority given to standard service as compared to the other classes of service and from the fact that standard routed data service equipment is often a considerable distance from a NASA operating location.

Note 4: These values apply only for those parts of the WAN service supported by the NISN mission services backbone infrastructure. These values do not apply to tail circuits unless the circuits/services were specifically ordered and supplied with diverse routing end-to-end.

Note 5: Round Trip Time (latency) is specified for data flow between WAN nodes controlled and operated by NISN. Latency is a function of distance and carrier capabilities. User applications that are sensitive to latency shall be engineered to account for the upper limit round trip times specified in the above table.

\section{Better than Best Effort (REN Provided)}

The following statistics in Table 2 are taken from the 7 day period starting 2006-03-09 and show the total amount of data sent across the Abilene network. These data are archived at the Internet2 Abilene Network Operation Center. As shown the aggregate traffic on Abilene is significant while the percentage of use is low. While this does not reflect what may be happening over a greater time frame it is indicative of the bandwidth that might be available to science and education. Although this may appear as over provisioning it is actually reflective of the fiber technology used.

\begin{tabular}{|c|c|c|c|c|}
\hline Date & - & $\frac{\underline{\text { Avg }}}{\underline{\text { Mbps }}}$ & $\frac{\%}{\underline{\text { Util }}}$ & $\begin{array}{c}\text { Total } \\
\text { Xfers in } \\
\text { Gbytes }\end{array}$ \\
\hline \multirow[t]{2}{*}{ 9-Apr } & In & $22,910.00$ & 2.727 & 241,629 \\
\hline & Out & $23,108.40$ & 2.751 & 243,722 \\
\hline \multirow[t]{2}{*}{ 8-Apr } & In & $24,191.40$ & 2.88 & 255,143 \\
\hline & Out & $24,386.50$ & 2.903 & 257,201 \\
\hline \multirow[t]{2}{*}{ 7-Apr } & In & $27,577.60$ & 3.283 & 290,858 \\
\hline & Out & $27,729.00$ & 3.301 & 292,454 \\
\hline \multirow[t]{2}{*}{ 6-Apr } & In & $27,397.70$ & 3.261 & 288,960 \\
\hline & Out & $27,583.40$ & 3.284 & 290,918 \\
\hline
\end{tabular}

${ }^{7}[2]$ nisn.msfc.nasa.gov/DocumentPages/Services.html 


$\begin{array}{lllll}\text { 5-Apr } & \text { In } & 27,955.50 & 3.328 & 294,843 \\ & \text { Out } & 28,139.90 & 3.35 & 296,788 \\ \text { 4-Apr } & \text { In } & 29,024.70 & 3.455 & 306,120 \\ & \text { Out } & 29,125.70 & 3.467 & 307,185 \\ \text { 3-Apr } & \text { In } & 27,355.10 & 3.256 & 288,511 \\ & \text { Out } & \underline{27,538.10} & \underline{3.278} & \underline{290,441} \\ \text { Total In } & & 26,630.30 & 3.17 & 280,866 \\ \text { Total Out } & & 26,801.60 & 3.191 & 282,673\end{array}$

Table 2, the Abilene Network Typical Utilization for the week of April 3-9, 2006

\section{Availability}

Operational specifications vary widely according to the network. For this paper we will investigate the Abilene Network in terms of availability, packet loss, latency and jitter. It must be recognized that any look into performance is only a snapshot. To accomplish this the week of April 3-9, 2006 and the preceding year has been selected because schools are in session and no holidays are near.

Availability for Abilene was $99.99791 \%$ for the year ending April 9, 2006. There has never been a failure which has resulted in a loss of availability to the Abilene user community. When failures occur, they are measured in milliseconds while traffic is rerouted usually without packet loss occurring. As mentioned above when Katrina took out the Atlanta to Houston link, no loss of service occurred as traffic was rerouted over other links to traverse east and west. Since the southern route was broken, making the Kansas City to Denver circuit a single point of failure, during the outage, a circuit was "borrowed" from the National Lambda Rail from Seatle to Chicago thus establishing another path until the Houston to Atlanta service was reestablished. Availability of regional networks is similar to Abilene. However some state RENs, especially during school hours, have congestion problems which limits their performance.

\section{Latency}

The Abilene network latency is measured one way for all nodes to all other nodes. Since Abilene is a fiber based network the latency between nodes is only limited by physics and is essentially the measured speed of light between nodes plus routing determinations along the way.

5. Jitter

Jitter is not measured on Abilene.

\section{Packet Loss}

The Abilene network essentially operates without any packet loss. In general, there is a relationship between packet loss and errors per second in that if there are no errors per second there follows that there is no packet loss occurring. As table TBD shows Abilene experienced virtually no packet loss during calendar year 2005 . The only time where loss did occur was when the circuit between Atlanta and Houston which goes through New Orleans was down for 9.5 days.

\begin{tabular}{|c|c|c|c|c|c|c|c|c|c|c|c|c|}
\hline & & atlanta & chicago & denver & houston & Indy & $\underline{K C}$ & $\underline{\text { LA }}$ & NYC & Sunvale & seattle & DC \\
\hline & atlanta & $\frac{0.0231}{0.00}$ & $\frac{7.6451}{0.00}$ & $\frac{15.680}{10.00}$ & $\frac{9.9951}{0.00}$ & $\frac{5.7501}{0.00}$ & $\frac{10.3561}{0.00}$ & $\frac{27.0901}{0.00}$ & $\frac{10.1991}{0.00}$ & $\frac{28.0351}{0.00}$ & $\frac{28.376 !}{0.00}$ & $\frac{8.0651}{0.00}$ \\
\hline & chicago & $\frac{7.8961}{0.00}$ & $0.023 I$ & $\frac{12.428}{10.00}$ & $\frac{14.299 /}{0.00}$ & & & $\frac{28.7851}{0}$ & & & $24.641 /$ & $\frac{12.2381}{0.00}$ \\
\hline & & 15.5891 & 13.0521 & 0.0231 & 13.5421 & 10.311 & $5.661 /$ & 17.2411 & 23.0731 & 13.6151 & $13.954 !$ & 25.2011 \\
\hline & denver & 0.00 & 0.00 & 0.00 & 0.00 & 0.00 & 0.00 & 0.00 & 0.00 & 0.00 & 0.00 & 0.00 \\
\hline & houston & $\frac{17.9501}{0.00}$ & $\frac{14.2821}{0.00}$ & $\frac{13.308}{10.00}$ & $\frac{0.0231}{0.00}$ & $\frac{12.392 /}{0.00}$ & $\frac{7.7731}{0.00}$ & $\frac{16.2931}{0.00}$ & $\frac{24.2981}{0.00}$ & $\frac{19.6651}{0.00}$ & $\frac{27.9571}{0.00}$ & $\frac{26.4271}{0.00}$ \\
\hline & Indy & $\frac{5.9511}{0.00}$ & $\frac{329.655}{10.00}$ & $\frac{12.877}{10.00}$ & $\frac{12.374 l}{0.00}$ & $\frac{0.0231}{0.00}$ & $\frac{4.6981}{0.00}$ & $\frac{26.5241}{0.00}$ & $\frac{11.9981}{0.00}$ & $\frac{22.3741}{0.00}$ & $\frac{22.7141}{0.00}$ & $\frac{14.1271}{0.00}$ \\
\hline & $\underline{\mathrm{KC}}$ & $\frac{11.0921}{0.00}$ & $\frac{6.6021}{0.00}$ & $\frac{5.4071}{0.00}$ & $\frac{7.7651}{0.00}$ & $\frac{4.7091}{0.00}$ & $\frac{0.0231}{0.00}$ & $\frac{21.8261}{0.00}$ & $\frac{16.6191}{0.00}$ & $\frac{17.7691}{0.00}$ & $\frac{18.1101}{0.00}$ & $\frac{18.7441}{0.00}$ \\
\hline & & & & & & & & & & & & \\
\hline
\end{tabular}

\footnotetext{
${ }^{8}$ [1] stryper.uits.iu.edu/abilene/aggregate/html/
} 


\begin{tabular}{|c|c|c|c|c|c|c|c|c|c|c|c|}
\hline & $\underline{0.00}$ & $\underline{0.00}$ & 10.00 & $\underline{0.00}$ & $\underline{0.00}$ & 0.00 & $\underline{0.00}$ & 0.00 & $\underline{0.00}$ & $\underline{0.00}$ & $\underline{0.00}$ \\
\hline NYC & $\frac{10.4281}{0.00}$ & $\frac{10.119 /}{0.00}$ & $\frac{21.980}{10.00}$ & $\frac{19.9261}{0.00}$ & $\frac{12.0371}{0.00}$ & $\frac{16.6471}{0.00}$ & $\frac{38.4211}{0.00}$ & $\frac{0.0231}{0.00}$ & $\frac{34.3251}{0.00}$ & $\frac{34.6641}{0.00}$ & $\frac{2.2211}{0.00}$ \\
\hline Sunvale & $\frac{28.2401}{0.00}$ & $\frac{352.237}{10.00}$ & $\frac{12.465}{10.00}$ & $\frac{19.6141}{0.00}$ & $\frac{22.3761}{0.00}$ & $\frac{17.7621}{0.00}$ & $\frac{4.2401}{0.00}$ & $\frac{34.2851}{0.00}$ & $\frac{0.0221}{0.00}$ & $\frac{8.3681}{0.00}$ & $\frac{36.416 /}{0.00}$ \\
\hline seattle & $\frac{28.4611}{0.00}$ & $\frac{24.790 I}{0.00}$ & $\frac{13.753}{10.00}$ & $\frac{27.9661}{0.00}$ & $\frac{22.8931}{0.00}$ & $\frac{18.2781}{0.00}$ & $\frac{12.565 /}{0.00}$ & $\frac{34.8021}{0.00}$ & $\frac{8.4421}{0.00}$ & $\frac{0.0241}{0.00}$ & $\frac{36.9351}{0.00}$ \\
\hline DC & $\frac{8.2951}{0.00}$ & $\frac{12.2511}{0.00}$ & $\frac{24.086}{10.00}$ & $\frac{17.7871}{0.00}$ & $\frac{14.1671}{0.00}$ & $\frac{18.8631}{0.00}$ & $\frac{33.9671}{0.00}$ & $\frac{2.225 I}{0.00}$ & $\frac{36.4551}{0.00}$ & $\frac{36.7961}{0.00}$ & $\frac{0.0231}{0.0}$ \\
\hline
\end{tabular}

Table 3, Abilene Latency (in ms)/Packet Loss Statistics (in \%) for IPv6 Traffic in Calendar Year $\mathbf{2 0 0 5}^{\mathbf{9}}$

\section{H. NISN to Abilene Comparison}

To demonstrate the adequacy of using RENs a comparison of the performance specification between NISN and Abilene is required. The following are specifications and measurements within the respective network backbones. In Table TBD below is a comparison of the actual performance of the Abilene network and the published performance specifications of the NISN network. NISN actual performance statistics are not available. For the purposes of this paper they are not germane. As can be observed the Abilene network availability exceeds all NISN categories including real time mission critical. Restoral times exceeded the NISN mission critical. It should be pointed out that restoral periods do not equate to loss of service, when restoral is defined as restoration of lost service is measured in milliseconds not minutes or hours to a user. The IU/PUI Network Operations Center operates 24 days, 7 days a week. The NISN packet loss for realtime mission critical of $.001 \%$ is exceeded by Abilene's $0 \%$ packet loss performance.

\begin{tabular}{|c|c|c|c|c|c|c|c|c|c|c|}
\hline & NISN & Abilene* & NISN & Abilene* & NISN & Abilene* & NISN & Abilene ${ }^{*}$ & NISN & Abilene* \\
\hline $\begin{array}{c}\text { Service } \\
\text { Category }\end{array}$ & $\underset{\text { (Percent) }}{\text { Availability }}{ }^{4}$ & & $\begin{array}{c}\text { Restoral } \\
\text { Time }^{4}\end{array}$ & $\begin{array}{c}\text { All } \\
\text { restorals } \\
\text { within } 2 \\
\text { hrs with } \\
\text { no service } \\
\text { break** }\end{array}$ & $\begin{array}{l}\text { Coverage } \\
\text { Period }\end{array}$ & $\begin{array}{l}\text { IU NOC } \\
\text { is } 24 X 7\end{array}$ & $\begin{array}{c}\text { Acceptable } \\
\text { Packet } \\
\text { Loss } \\
\text { (Percent) }\end{array}$ & $\begin{array}{c}0 \\
\text { Packet } \\
\text { Loss }\end{array}$ & $\begin{array}{c}\text { Round } \\
\text { Trip } \\
\text { Time }^{5}\end{array}$ & $\begin{array}{c}\text { Between } \\
\text { Nodes }\end{array}$ \\
\hline $\begin{array}{l}\text { Real- } \\
\text { time } \\
\text { Critical }\end{array}$ & 99.98 & 99.9979 & $<1 \min ^{1}$ & $\therefore$ & $24 \times 7$ & & 0.001 & 0 & $\begin{array}{c}<120 \\
\mathrm{~ms}\end{array}$ & $\begin{array}{l}\text { Worst } \\
\text { Case for } \\
\text { the week } \\
\text { of } 4 / 9 / 06 \text { : } \\
38 \text { ms one } \\
\text { way }\end{array}$ \\
\hline $\begin{array}{l}\text { Mission } \\
\text { Critical }\end{array}$ & 99.95 & & $2 \mathrm{hr}^{2}$ & & $24 \times 7$ & & 0.001 & & $\begin{array}{c}<120 \\
\mathrm{~ms}\end{array}$ & \\
\hline Premium & 99.5 & & $4 \mathrm{hr}^{2}$ & & $24 \times 7$ & & $<1.0$ & & $<100$ & \\
\hline Standard & 99.5 & & $<24 \mathrm{hr}^{2,3}$ & & $\begin{array}{l}6 \quad \text { a.m. } \\
\text { Eastern } \\
\text { Monday } \\
\text { to } 6 \text { p.m. } \\
\text { Pacific, } \\
\text { Friday }\end{array}$ & & 1 & & $\begin{array}{c}<250 \\
\mathrm{~ms}\end{array}$ & \\
\hline
\end{tabular}

* Actual performance

** Except Katrina (9.5 day restoral time)

*** Between Abilene backbone nodes

\section{Table 4, the Abilene Network and NISN Performance Comparison}

In an attempt to quantify what the NISN specification compared to the Abilene performance statistics for the week of April 3-9, 2006 a comparison is presented in Table 4 based on the traffic presented in Table 2 for the week of April 3-9, 2006. What is presented is what would be allowed under the NISN Real time mission critical service in

\footnotetext{
${ }^{9}[1]$ ndb1-Imt.abilene.ucaid.edu/ami/owamp_status.cgi/14231676561123180544_14411656736165330944
} 
effect as of May 2006. Packet loss is based on 563,539 Gbytes of traffic in and out of Abilene. The availability is based on a one week timeframe. The Abilene latency is based on the worst case for calendar year 2005 between NYC and LA.

\begin{tabular}{|l|l|l|l|}
\hline & NISN & Abilene & \\
\hline & Allowable & Actual & \\
\hline Packet Loss & 54,789 & 0 & Packets for the week \\
\hline Availability & 120.96 & $0^{*}$ & Seconds for the week \\
\hline Latency & 120 & $76^{* *}$ & ms round trip \\
\hline & & & \\
\hline * not added are the few ms associated with re-routing \\
\hline ** worst case between NYC and LA during CY05 \\
\hline
\end{tabular}

Table 5, quantifying the NISN performance specification against the Abilene Performance for the week of April 3-9, 2006

\section{REN Security}

Security of the network itself is the responsibility of the individual RENs. Denial of Service attacks do occur at the end networks and hackers do at times use the Abilene network to conduct their attacks. That said the NOC and Global NOC are on a constant vigil and work with the responsible entities to combat these types of attacks. As with most aspects of security, the Abilene Network does not divulge specific security mechanisms that are in place.

Security for user data is the responsibility of the user.

\section{Future Technologies and Bandwidth Availability}

For potential science users a question should be asked: What about the future? Generally speaking bandwidth in networking is becoming a non issue. In the future Dense Wave Division Multiplexing will be serving up almost limitless bandwidth. Of course as bandwidth becomes available so does the applications to eat it up! Currently DWDM based technologies are installed at the trunk level within a networks infrastructure. Light based switching and routing will allow faster and more reliable distribution including distribution to the desktop. Fiber to the desktop will enable desktop ingest speeds unheard of today. Network technologies are evolving rapidly and should provide adequate bandwidth for years to come.

\section{Brief Overview of ISS REN Use and the Solar B Satellite Planned Use}

The International Space Station's Payload Operations Integration Center (POIC) located at the Marshall Space Flight Center in Huntsville, Alabama is the focal point for all ISS based science operations. Since November of 2001, the POIC has coordinated all ISS scientific activities. This includes receipt of telemetry from ISS and distributing it to the various principle investigators throughout the USA. Also all voice operations between the ISS crew and PIs is conducted through the POIC. Downlink video from ISS in the form of two $4 \mathrm{Mbps}$ streams is received via multicast from the Johnson Space Center to MSFC and PIs. PIs command their instruments via the POIC. Most POIC to PI operations is conducted over the Abilene network.

"Solar-B is the follow-up mission to the very successful Japan/UK/US Yohkoh mission. Using a combination of optical, EUV and X-ray instrumentation Solar-B will study the interaction between the Sun's magnetic field and its corona to increase our understanding of the causes of solar variability. It is due for launch in September 2006. Included in Solar-B's instrumentation is a $0.5 \mathrm{~m}$ optical telescope, an EUV imaging spectrometer and an X-ray/EUV telescope. The instruments will work together as an observatory." 10

The Solar B network requirements are divided into two categories, immediate post launch and then the on going science operations. The first category is to provide network support for satellite test and checkout just after launch. Figure 4 depicts the overall connectivity that exists which can support Solar B. During the initial satellite checkout period, scheduled for up to 20 days after launch, data from the satellite will be received at ground receiving stations

${ }^{10}[5]$ www.mssl.ucl.ac.uk/www solar/solarB 
at Santiago Chile, Wallops Island Maryland, and several other Japanese ground stations. The plan is to receive realtime flows from Santiago and Wallops through Goddard Space Flight Center that contains engineering telemetry necessary to assess spacecraft conditions and to make any necessary adjustments. These flows will be routed to MSFC where they will be available by FTP to Japan through existing HOSC systems.

Once the satellite has been checked out and is operational, telemetry will flow ( $\mathrm{x}$ band) from satellite receiving stations in Svalbard, Norway and Japan to the Solar B control center in Sagamihara Japan. This $\mathrm{x}$ band flow will be transmitted several times per day for the life of the satellite. Once received at the Solar B control center the data will be decommutated (separated by instrument) and the instrument specific data will be sent to three locations in the USA, one in Britain and one in Norway for archiving and access by scientists. Also a database will be maintained in Japan. Once databased at one of these locations, this science data can be accessed by anyone authorized to receive it. It is estimated that up to $30 \mathrm{~Gb}$ of telemetry will be transmitted daily to Japan from the satellite and comparable flows to the archiving locations and from the archiving locations to the scientific community. These $\mathbf{x}$ band flows to and from Japan will be over the RENs listed in Appendix A.

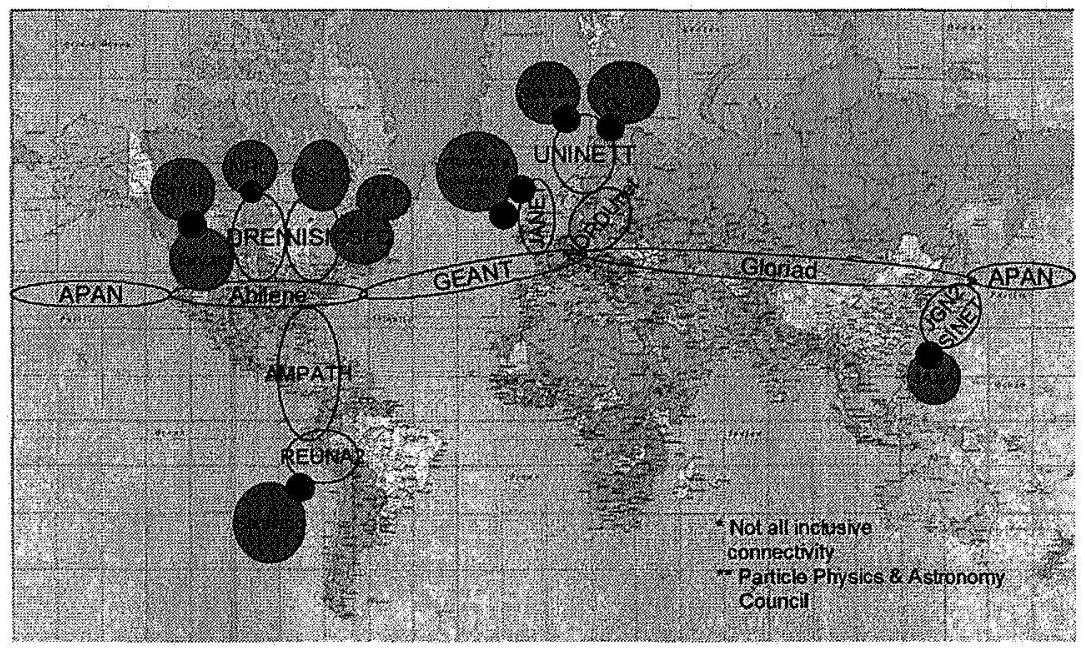

Figure 4, Solar B Worldwide Connectivity

\section{In Conclusion}

The benefits of REN use are many. RENs especially in the industrialized world perform equal to or exceed the space operations network specifications required to support even critical space operations. The overall cost is minimal. The connectivity is everywhere and growing. The underlying technology is cutting edge but not bleeding edge and allows more bandwidth availability than demand.

The performance of the Abilene network and generally of national and international RENs is more than adequate to support space based science operations for science conducted on manned and unmanned vehicles and satellites. It meets or exceeds the NISN published performance specifications for real time mission ops. The worst case one way latency far exceeds the NISN specification e.g. $38 \mathrm{~ms}$ worst case one way latency between NYC and LA for week of April 3, 2005. Abilene virtually experiences no packet loss and for one year prior to the April 3 week had a 99.997\% availability with no interruption of service. The network possesses adequate bandwidth based on utilization stats and its technology base. It uses advanced networking technologies while continuing to plan for the future.

It needs to be emphasized that using RENs does not replace use of NISN mission critical services where loss of network services equates to loss of life or mission e.g. loss of a satellite. As already mentioned RENs do not replace commercial network services but are in place to support research and education. Quit simply, RENs can provide the research data to end users and on most RENs to government research institutes and governmental RENs. Access to data by the research community (regardless of discipline) is essential to scientific collaborations. As shown, connectivity is worldwide, with stellar performance that enables collaboration at many levels. Voice and video conferencing, data sharing and access to analysis and scientific results is transmitted and received instantaneously. All without the need to purchase network services or circuits that avoids the cost and resources which would be 
required to procure and operate individual networks/circuits. These costs would be significant especially if every scientific collaboration was required to implement dedicated network services. Every dollar saved is a dollar that can be applied to the scientific endeavor. As seen the network performance of Abilene is more than adequate to support virtually any type of space based scientific endeavor.

However, there are a few minor drawbacks against REN use. Specifically, the lack of "control" most government agencies crave is not present. However, there is a significant amount of cooperation between networks. No centralized end to end control authority exists although significant cooperation exists between national, regional and intercontinental RENs. And finally, support could dry up if funding became difficult due to international politics.

A word of caution be careful not to spoil the REN opportunity by abusing it. Don't use it for purposes other than those that have been published in the Conditions of Use. 


\section{Appendix A, Solar B Network Maps}

The Chilean and Norwegian maps are unavailable due to language barriers and their Internet sites do not provide maps.

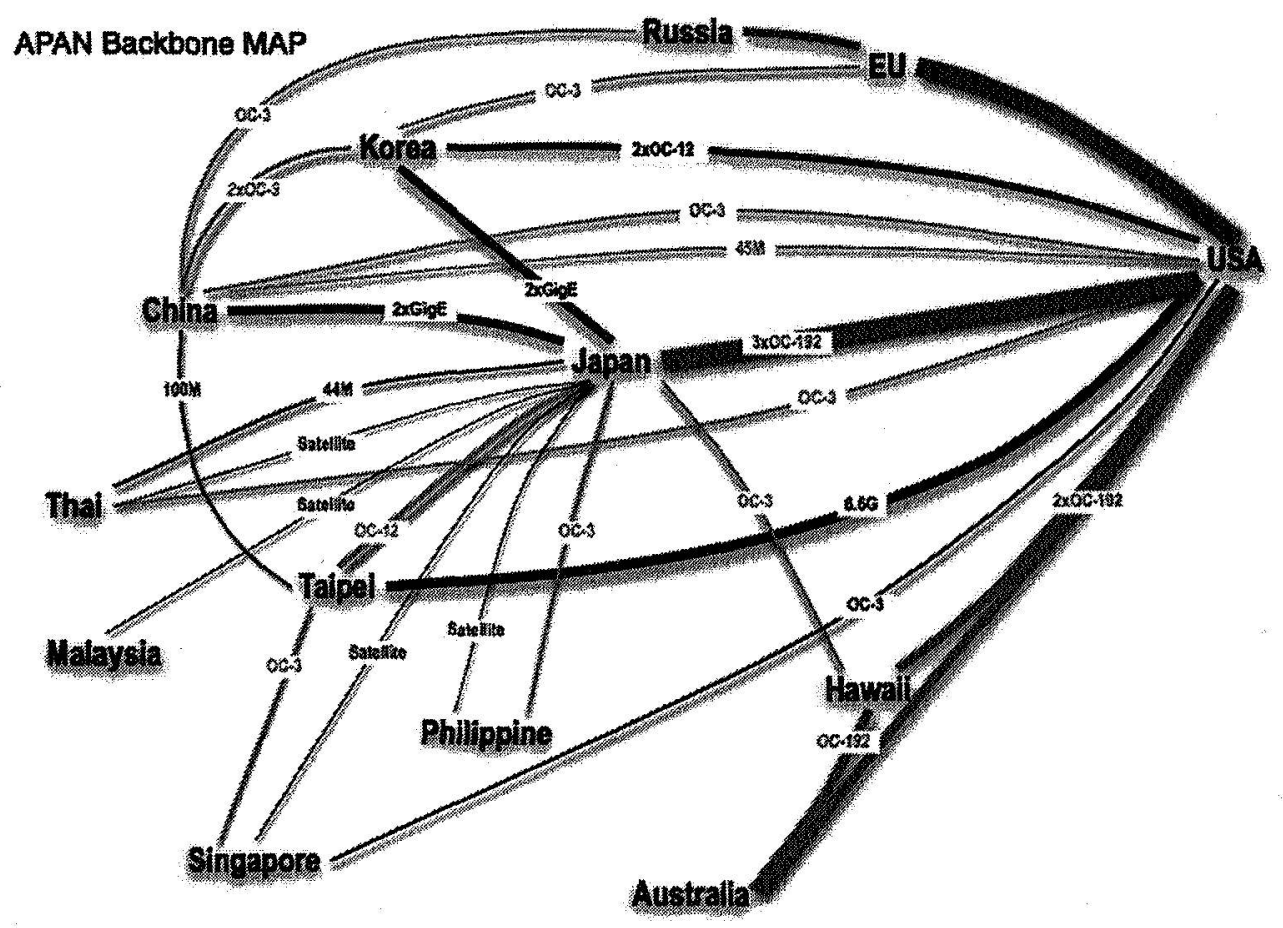

Figure 5, the Asia Pacific Advanced Network ${ }^{11}$

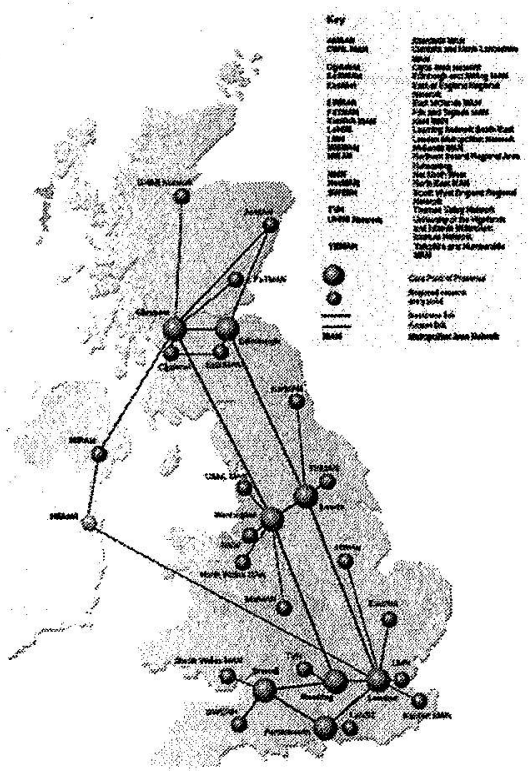

Figure 6, JANET, the Research and Education Network of Great Britain ${ }^{12}$

${ }^{11}[4]$ www.jp.apan.net/NOC/implementation/BackboneMap.html 
Composition Figure (Japan Map)

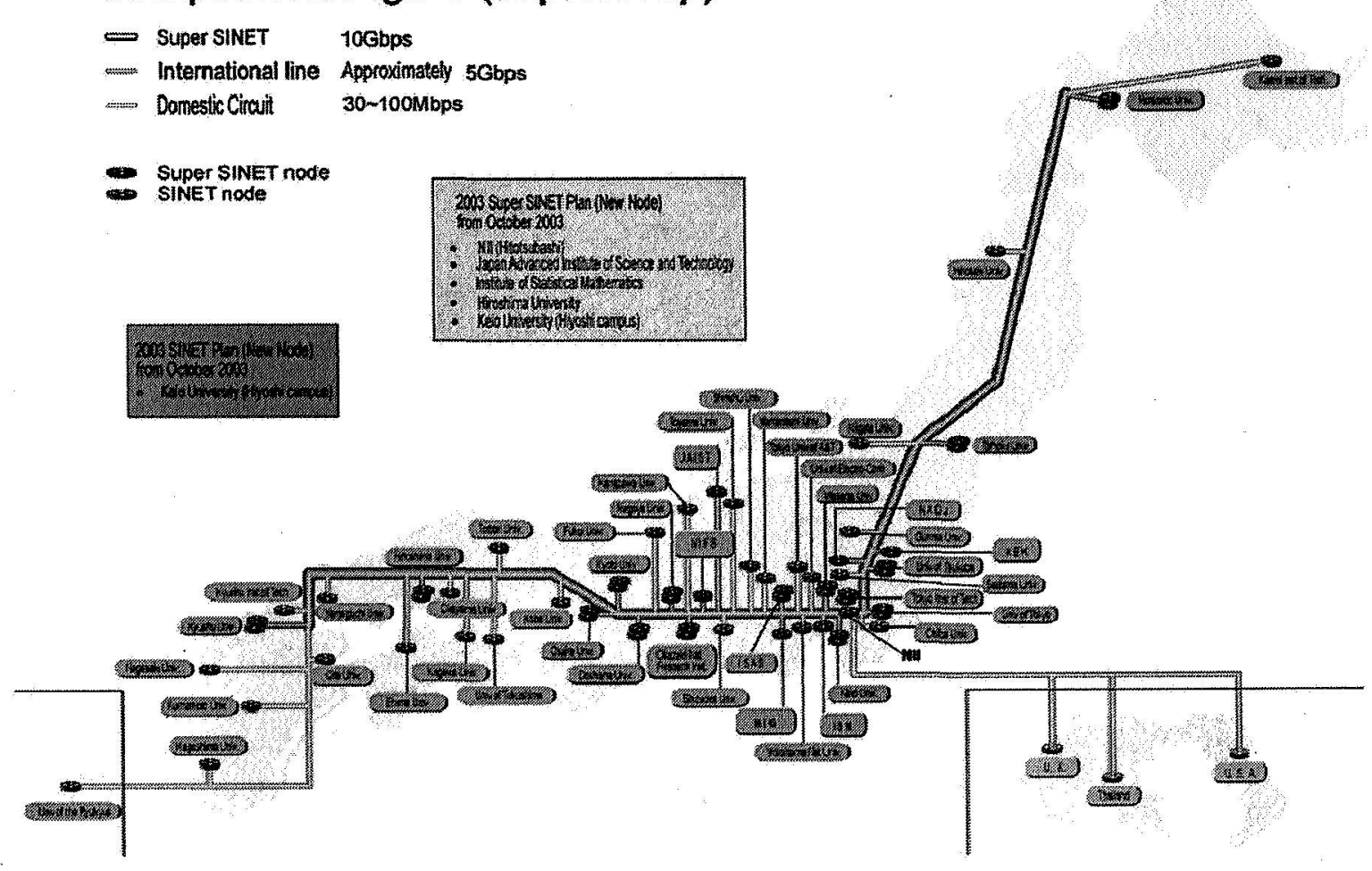

Figure 7, SInet the Japanese Research and Education Network ${ }^{13}$

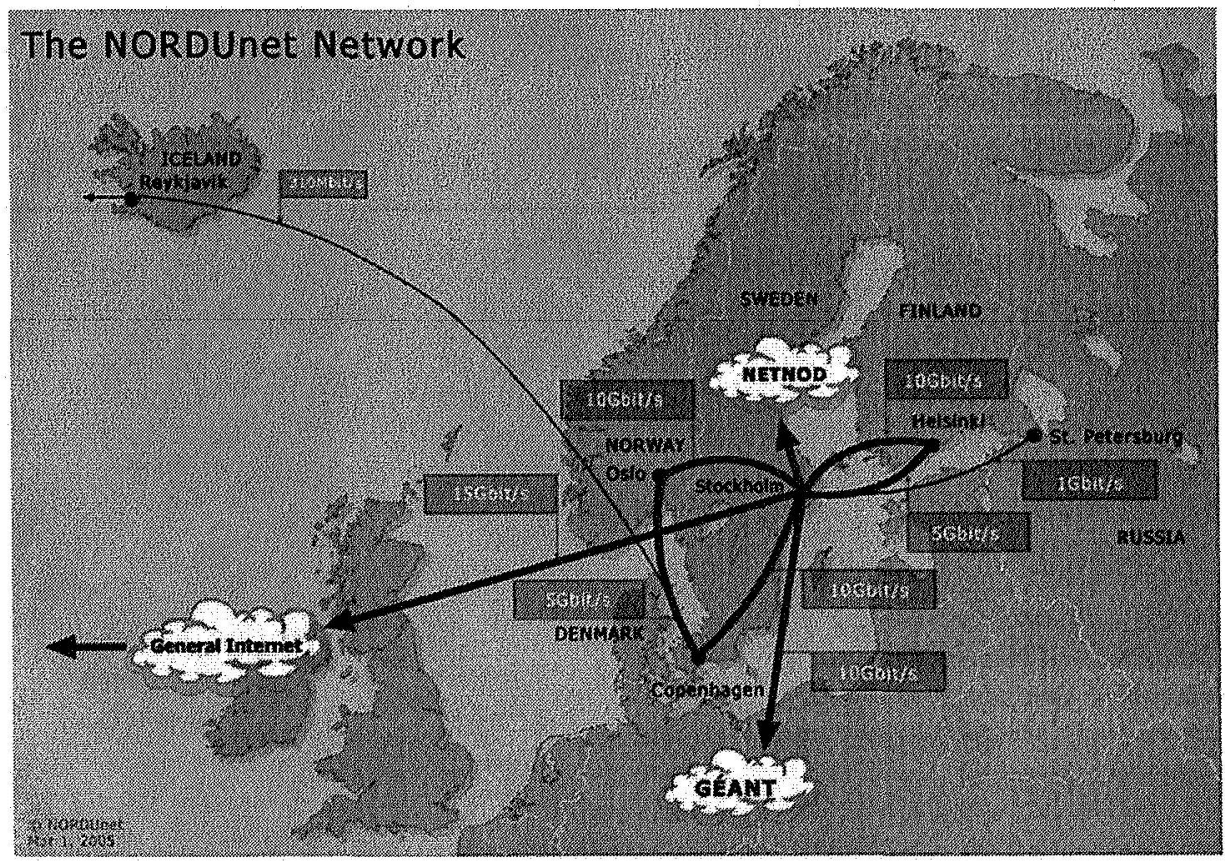

Figure 8, NORDUnet the Scandinavian Regional Research and Education Network ${ }^{12}$

${ }_{13}^{12}[6]$ www.ja.net/about/topology/janet-backbone-\&-key-oct-05.pdf

${ }^{13}$ [7] www.sinet.ad.jp/english/s sinet promotion conference.html 


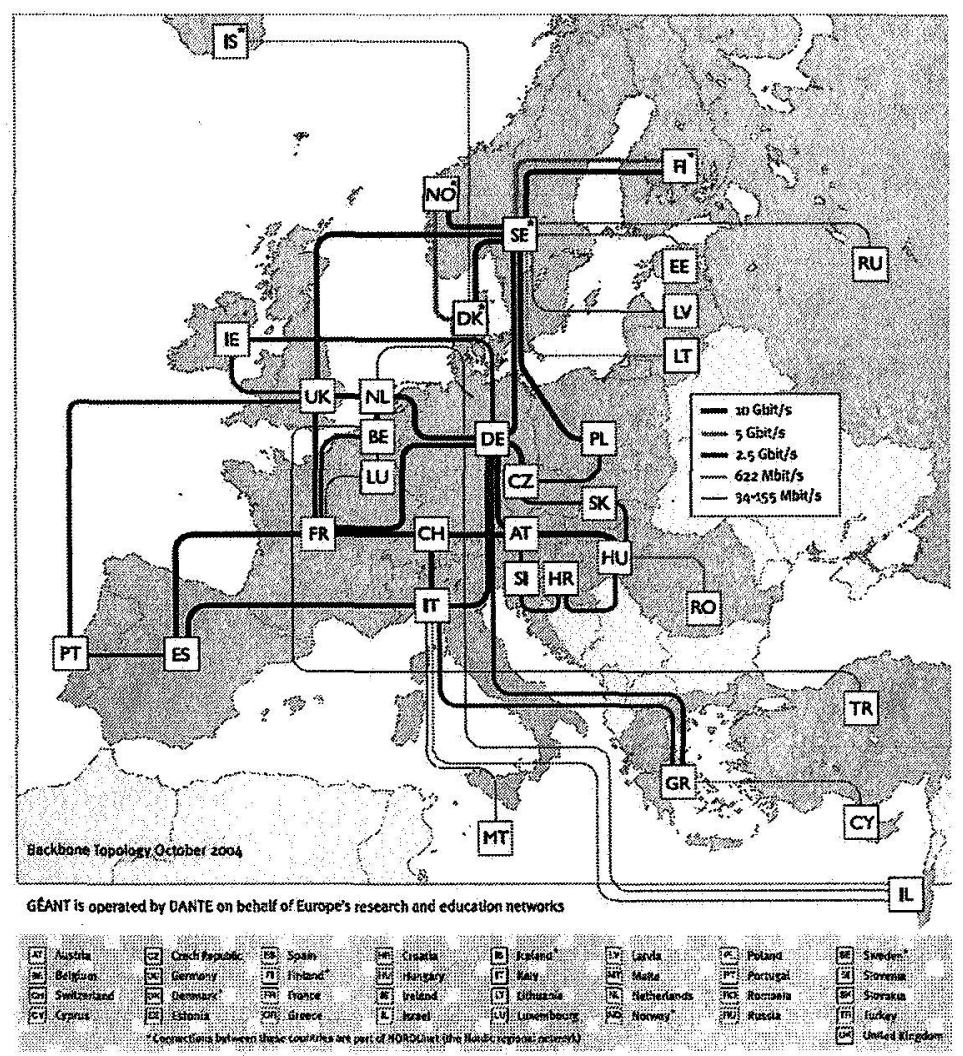

Figure 9, GEANT, the European REN and transatlantic connectivity to the US ${ }^{14}$

\section{Acknowledgments}

The author would like to acknowledge the contributions of Eric Boyd, Rich Carlson, Matt Zekauskas and Jim Williams of Internet2 and the Indiana University/Purdue University at Indianapolis Network Operations Center for providing data of Abilene performance, pointing us in the right direction.

\section{References}

[1] "Indiana University Abilene Network Operations Center, Network Monitoring," Network Monitoring Databases [online databases] [www.abilene.iu.edu/noc.html. Accessed 5/18/2006.]

[2] "NISN Services Document," Marshall Space Flight Center, Alabama, 2005. [http://nisn.msfc.nasa.gov. Accessed 5/16/2006.]

[3] "GEANT Topology," Cambridge, United Kingdom, 2006. [www.geant.net. Accessed 4/12/2006.]

[4] "Asia Pacific Advanced Network Topology," Bangkok, Thailand, 2006. [

[www.apan.net/documents/network-topology-8.1.ppt. Accessed 2/8/2006.]

[5] "An ISAS/NASA/PPARC mission to study the Sun" Tokyo, Japan, 2006.

[www.mssl.ucl.ac.uk/www solar/solarB. Accessed 2/9/2006.]

[6] "JANET in the UK Network Topology," Oxfordshire, United Kingdom, 2006. [www.ja.net/about/topology/. Accessed 3/18/2006.]

[7] "Science Information Network," Tokyo, Japan, 2006. [www.sinet.ad.jp/english/. Accessed 3/19/2006.]

${ }^{14}[3]$ www.geant.net/upload/pdf/Topology_Oct 2004.pdf 


\section{A Space Operations Network Alternative: Using Globally Connected Research and Education Networks for Space-based Science Operations}

Robert N. Bradford

Mission Operations Laboratory

256-544-2843

robert.n.bradford@nasa.gov

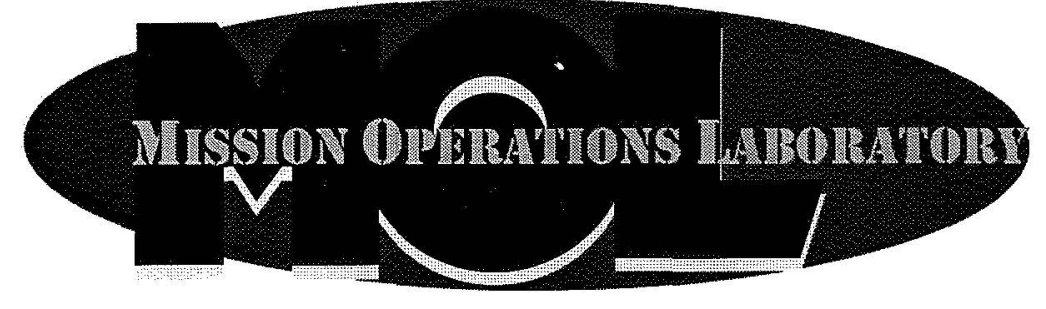




\section{Introduction}

- Purpose of this Paper

- Encourage you to investigate using RENs in space-based science ops

- How they can benefit space based science

- How to quantify a justification for REN use

- Compare the USA's REN to the NISN published network performance characteristics

- Demonstration in actual and planned space-based use

+ International Space Station use

+ Discuss the planned use by the Solar B Satellite project

Why?

- Use a high performance network while,

- Significantly lowering communication costs

- Question not addressed but should be asked: Are they good enough for manned flight network operations?

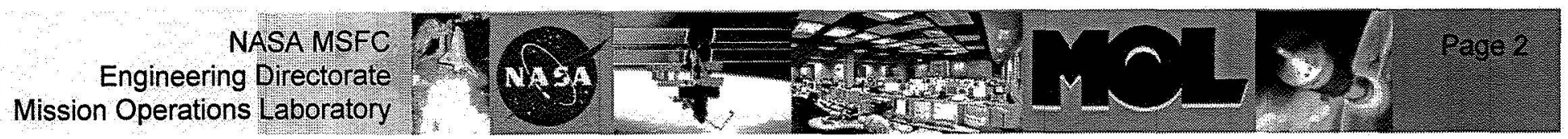




\section{Background}

$\checkmark$ History Lesson:

- Precursor to the Internet

- First US based REN established by NSF: vBNS in the early 90's

- In 1996 Internet2 was established through UCAID

- Internet2/Abilene replaced vBNS

- About Internet2 and Abilene the USA Research and Education Network

- Internet2 is membership based

- Memberships are layered

+ prime members are colleges and universities

+ Affiliate members sponsored by a prime can be government, corporate and other non profits

- Membership and connection fees apply 


\section{Discussion of Research and Education Networks}

- Purpose of RENs

They exist to provide network connectivity for research and educational purposes

- They do not support the commodity Internet.

- Research covers a wide range of disciplines from networking research to discipline specific scientific research.

- Education covers all aspects of education, including access to information, streaming video, voice, collaborations and online teaching. 


\section{Discussion of Research and Education Networks}

\section{$\checkmark$ REN Organization}

- RENs are national, regional and then international

- Besides networking, heavy emphasis on applications within Internet2

- No worldwide centralized REN organization

+ Many organizations and associations recognize RENs and use them extensively

$\diamond$ GGF, .... High Energy Physics

- In the US the controlling authority is UCAID/Internet2 with regional/international organizations

+ Europe: GEANT

+ Asia and Oceania: APAN

+ South America: AMPATH

+ Russia: Gloriad

- They exist because of the common need to collaborate and transfer research and educational information and data

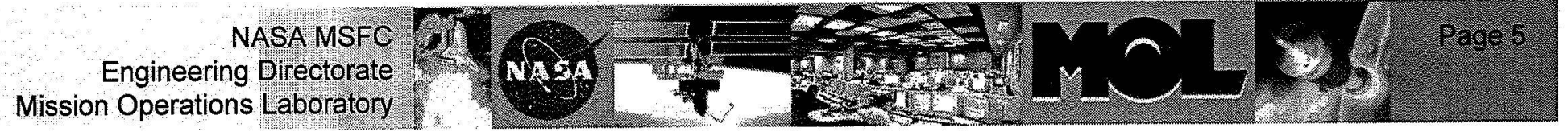




\section{Discussion of Research and Education Networks}

- Conditions of Use (CofU) Policies

- Use must be related to scientific and network research and education

- Membership restrictions vary between national and international entities

- However, when traversing other networks to get to a far away end point membership in all networks being traversed is generally not required

- Membership in one REN generally is recognized by all others 


\section{Discussion of Research and Education Networks}

- Current Network Services Provided by RENs

- Network operations

IPv6

Multicast

- QoS

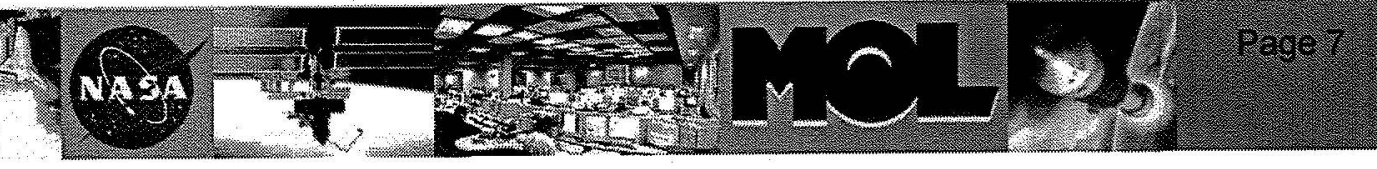




\section{Discussion of Research and Education Networks}

- Abilene Connectivity Overview with the Abilene 10Gb Backbone in Red
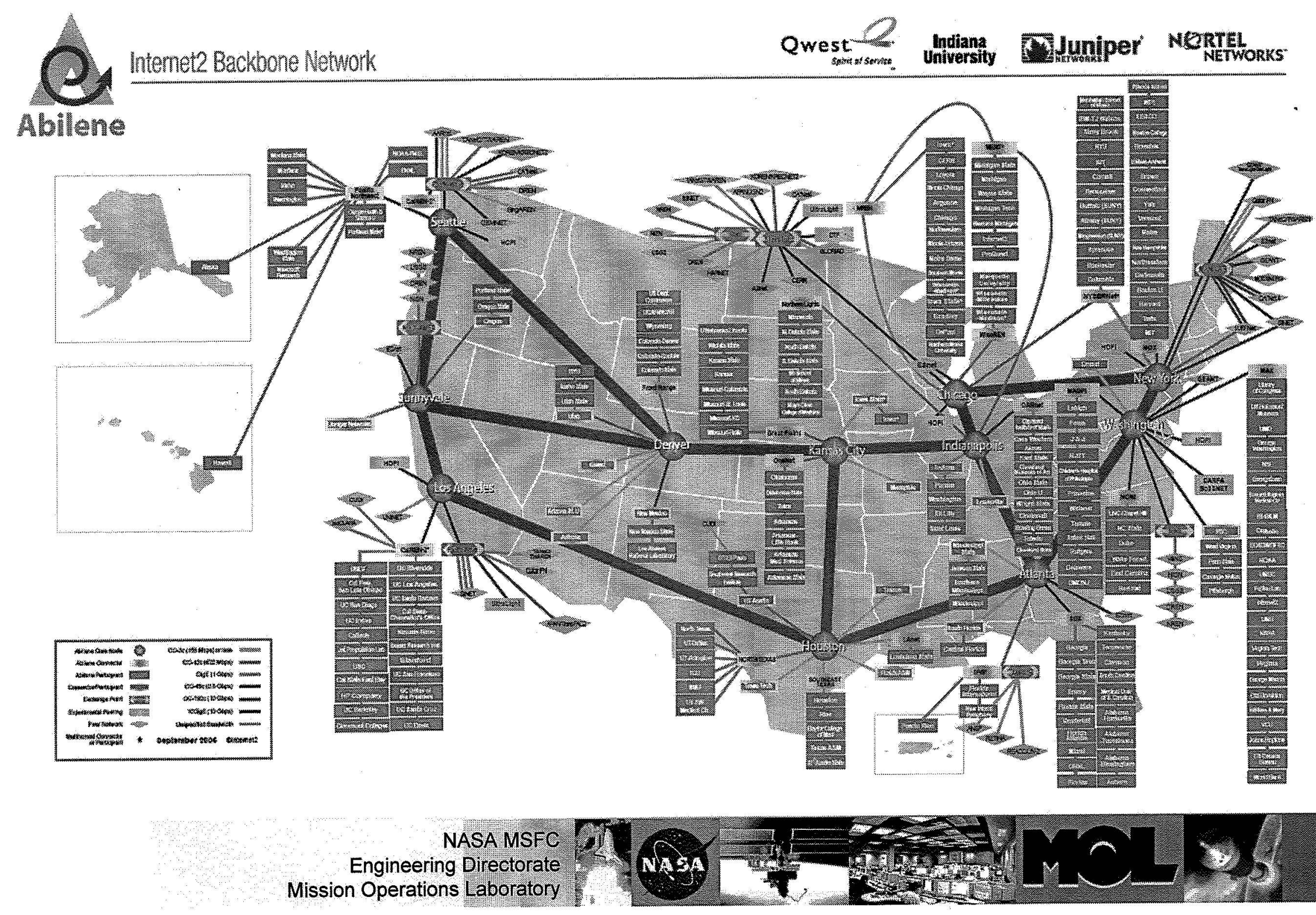


\section{Discussion of Research and Education Networks}

\section{- Abilene International Connectors Abilene International Network Peers}

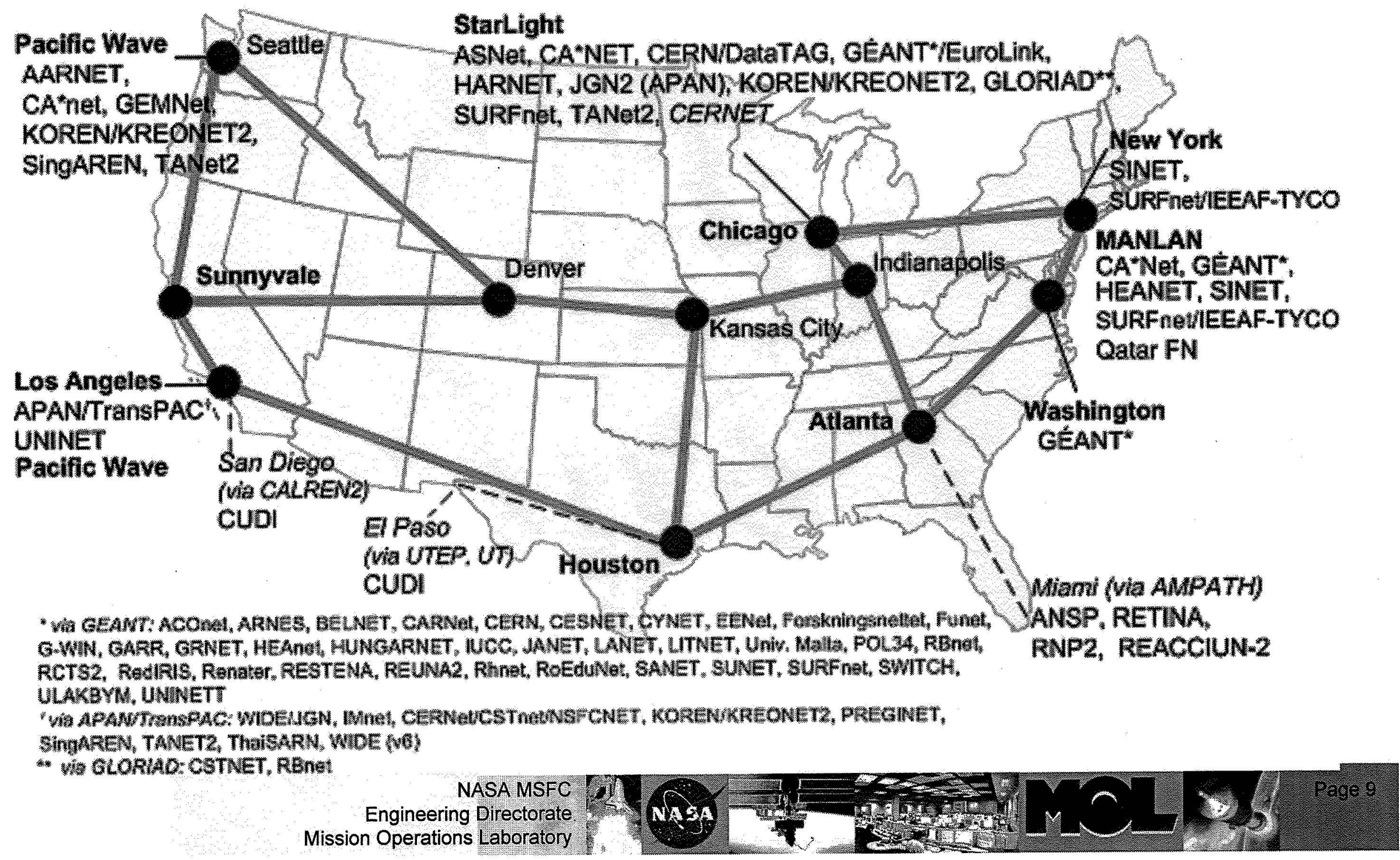




\section{The NISN and Abilene Comparison}




\section{Comparing What?}

- NISN Published Performance Specs to Abilene Performance Comparison

- Availability: The time expressed in percentage that the network is supporting users and does not include scheduled maintenance downtime

- Latency: The time expressed in milliseconds that it takes a timed packet to traverse the network either one way (Abilene) or round trip (NISN)

- Jitter: The variation in packet arrival time at an end point (not compared because NISN currently does not specify jitter and Abilene does not provide measurements)

- Packet Loss: The amount of lost packets expressed in percentage over a specific time frame 


\section{The NISN and Abilene Comparison}

- NISN Published Performance Specifications for the:

- Four levels of NISN Internet Protocol (IP) services and their uses:

+ Real Time Mission Critical - NW outage could result in loss of crew and/or vehicle

+ Mission Critical - NW outage could result in loss of, or impact to mission objectives

+ Premium IP - Administrative between Centers

+ Standard IP - equivalent to the Internet

\section{Compared Against}

- Abilene Archived Performance Statistics at the Real Time Mission Critical service level 


\section{The Comparison}

NISN Published Performance Specifications

\begin{tabular}{|c|c|c|c|c|c|}
\hline $\begin{array}{c}\text { Service } \\
\text { Category }\end{array}$ & $\begin{array}{c}\text { Availability }^{4} \\
\text { (Percent) }\end{array}$ & $\begin{array}{c}\text { Restoral } \\
\text { Time }^{4}\end{array}$ & Coverage Period & $\begin{array}{c}\text { Acceptable } \\
\text { Packet Loss } \\
\text { (Percent) }\end{array}$ & Round Trip Time 5 \\
\hline $\begin{array}{l}\text { Real-time } \\
\text { Critical }\end{array}$ & 99.98 & $<1 \min ^{1}$ & $24 \mathrm{X} 7$ & 0.001 & $<120 \mathrm{~ms}$ \\
\hline Mission Critical & 99.95 & $2 \mathrm{hr}^{2}$ & $24 \times 7$ & 0.001 & $<120 \mathrm{~ms}$ \\
\hline Premium & 99.50 & $4 \mathrm{hr}^{2}$ & $24 \mathrm{X} 7$ & $<1.0$ & $<100 \mathrm{~ms}$ \\
\hline Standard & 99.50 & $<24 \mathrm{hr}^{2,3}$ & $\begin{array}{l}6 \text { a.m. Eastern } \\
\text { Monday to } 6 \text { p.m. } \\
\text { Pacific, Friday }\end{array}$ & 1.0 & $<250 \mathrm{~ms}$ \\
\hline
\end{tabular}




\section{Representative Week of Abilene Utilization (April 3-9, 2006)}

$\begin{array}{llccc}\text { Date } & & \underline{\underline{\text { Avg Mlbps }}} & \text { \% Util } & \begin{array}{c}\text { Total Xfers } \\ \text { in Gbytes }\end{array} \\ \text { 9-Apr } & \text { In } & 22,910.00 & 2.727 & 241,629 \\ & \text { Out } & 23,108.40 & 2.751 & 243,722 \\ \text { 8-Apr } & \text { In } & 24,191.40 & 2.88 & 255,143 \\ & \text { Out } & 24,386.50 & 2.903 & 257,201 \\ \text { 7-Apr } & \text { In } & 27,577.60 & 3.283 & 290,858 \\ & \text { Out } & 27,729.00 & 3.301 & 292,454 \\ \text { 6-Apr } & \text { In } & 27,397.70 & 3.261 & 288,960 \\ & \text { Out } & 27,583.40 & 3.284 & 290,918 \\ \text { 5-Apr } & \text { In } & 27,955.50 & 3.328 & 294,843 \\ & \text { Out } & 28,139.90 & 3.35 & 296,788 \\ \text { 4-Apr } & \text { In } & 29,024.70 & 3.455 & 306,120 \\ & \text { Out } & 29,125.70 & 3.467 & 307,185 \\ \text { 3-Apr } & \text { In } & 27,355.10 & 3.256 & 288,511 \\ & \text { Out } & \underline{27,538.10} & \underline{3.278} & \underline{290,441} \\ \text { Total In } & & 26,630.30 & 3.17 & 280,866 \\ \text { Total Out } & & 26,801.60 & 3.191 & 282,673\end{array}$




\section{Quantifying the NISN Spec against the Abilene Utilization for the week of April 3, 2006}

- NISN allowable under current specification in effect as of late May

- Packet loss based on 281,770 Gbytes of traffic in and out of Abilene

- Availability based on a one week timeframe

- Abilene latency based on worst case between DC and LA in CY05

\begin{tabular}{rccll} 
& NISN & Abilene & \\
& Allowable & Actual & \\
\cline { 2 - 3 } Packet Loss & 54,789 & 0 & Packets for the week \\
Availability & 120.96 & $0^{*}$ & Seconds for the week \\
Latency & 120 & $76^{* *}$ & ms round trip
\end{tabular}

* not added are the few ms associated with re-routing

** worst case between NYC and LA during CY05 


\section{The Comparison}

\begin{tabular}{|c|c|c|c|c|c|c|c|c|c|c|}
\hline & NISN & Abilene* & NISN & Abilene* & NISN & Abilene* & NISN & Abilene ${ }^{*}$ & NISN & Abilene* \\
\hline $\begin{array}{c}\text { Service } \\
\text { Category }\end{array}$ & $\begin{array}{c}\text { Availability } \\
\text { (Percent) }\end{array}$ & & $\begin{array}{c}\text { Restoral } \\
\text { Time }\end{array}$ & & $\begin{array}{c}\text { Coverage } \\
\text { Period }\end{array}$ & & $\begin{array}{c}\text { Acceptable } \\
\text { Packet Loss } \\
\text { (Percent) }\end{array}$ & & $\begin{array}{l}\text { Round } \\
\text { Trip } \\
\text { Time }\end{array}$ & \\
\hline$\cdot$ & & & & & & & & & & \\
\hline $\begin{array}{l}\text { Real-time } \\
\text { Critical }\end{array}$ & 99.98 & 99.9979 & $<1 \min ^{1}$ & $\begin{array}{l}\text { All restorals } \\
\text { within } 2 \text { hrs } \\
\text { with no } \\
\text { Interruption } \\
\text { of service** }\end{array}$ & $24 \mathrm{X} 7$ & $\begin{array}{l}\text { IU NOC } \\
\text { is } 24 X 7\end{array}$ & 0.001 & $\begin{array}{l}\text { O Packet } \\
\text { Loss }\end{array}$ & $<120 \mathrm{~ms}$ & $\begin{array}{l}\text { Worst Case } \\
38 \text { ms one } \\
\text { way }\end{array}$ \\
\hline $\begin{array}{l}\text { Mission } \\
\text { Critical }\end{array}$ & 99.95 & & $2 \mathrm{hr}$ & & $24 X 7$ & & 0.001 & & $<120 \mathrm{~ms}$ & \\
\hline Premium & 99.5 & & $4 \mathrm{hr}$ & & $24 \times 7$ & & $<1.0$ & & $<100 \mathrm{~ms}$ & \\
\hline Standard & 99.5 & & $<24 \mathrm{hr}$ & & $\begin{array}{l}6 \text { a.m. } \\
\text { Eastern } \\
\text { Monday to } \\
6 \text { p.m. } \\
\text { Pacific. } \\
\text { Friday }\end{array}$ & & 1 & & $<250 \mathrm{~ms}$ & \\
\hline
\end{tabular}

* actual performance

** except Katrina ( 9.5 day restoral time)

*** between Abilene backbone nodes

$$
\text { NASA MSFC }
$$

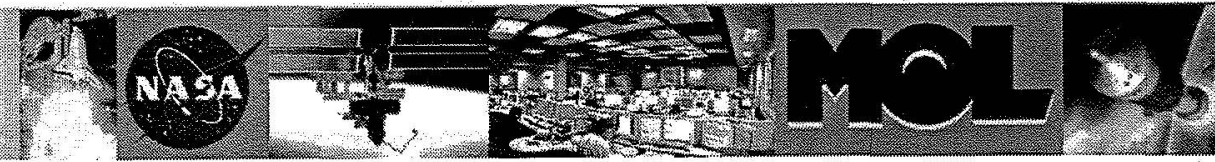




\section{Abilene Latency (in ms)/Packet Loss Statistics (in \%) for IPv6 Traffic in Calendar Year 2005}

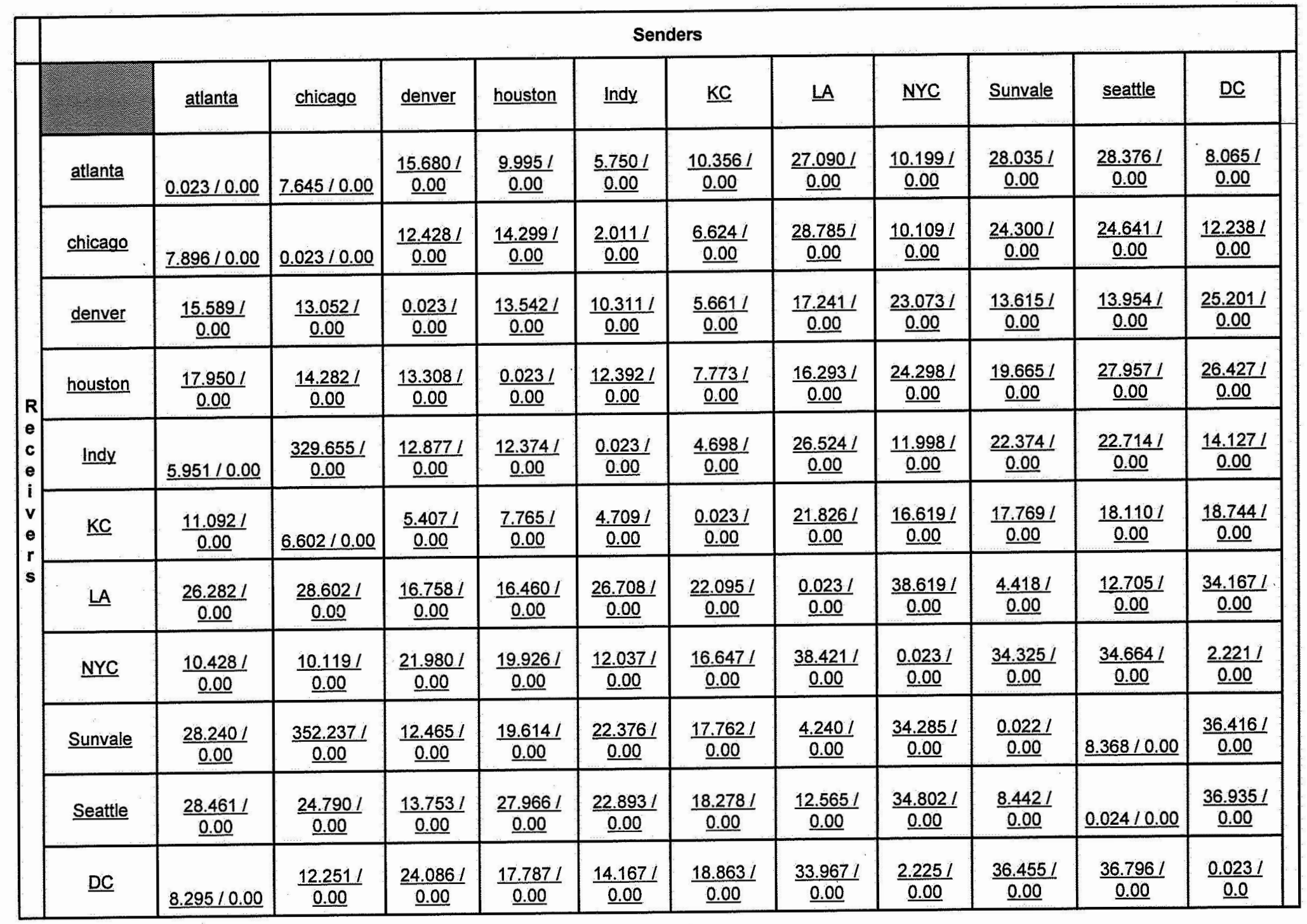

NASA MSFC 


\section{Demonstration of One Actual and One Planned Use of a REN: Brief Overview of current ISS Real-time Science Ops and the Solar B Satellite Planned Use}

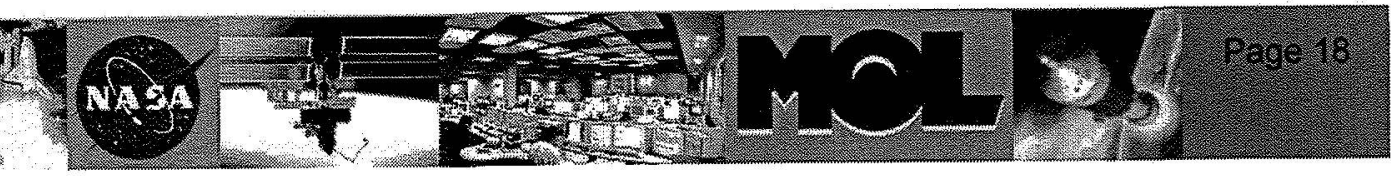




\section{International Space Stations (ISS)}

- ISS uses Abilene to conduct all ISS on board science operations since Fall of 2001

$\checkmark$ Distributes via Abilene:

- All telemetry to most Principle Investigators (PIs)

- Mission voice between ground cadre and PIs

- Space to Ground voice between PIs and on board crew

- Two MPEG2 multicast ISS downlink video flows at 4Mb each

- Commanding of experiments

- Never experienced a network outage that resulted in a service interruption with Abilene even during Katrina

- Cost to ISS Program: \$20K/year (cost of the Affiliate Membership) 


\section{Solar B Satellite}

- Planned uses (launch September 2006)

- Distribute from the Svalbard Norway ground station to Japan $X$ band telemetry from the satellite

- Distribute $X$ band telemetry from Japan to 3 instrument sites in the US, one in the UK and one in Norway

$\checkmark$ Distribute instrument data from the five instrument sites to scientists world wide

- Investigating the distribution, via FTP, of engineering telemetry $(L+20$ days) for satellite test and checkout 


\section{Worldwide Connectivity for Solar B}

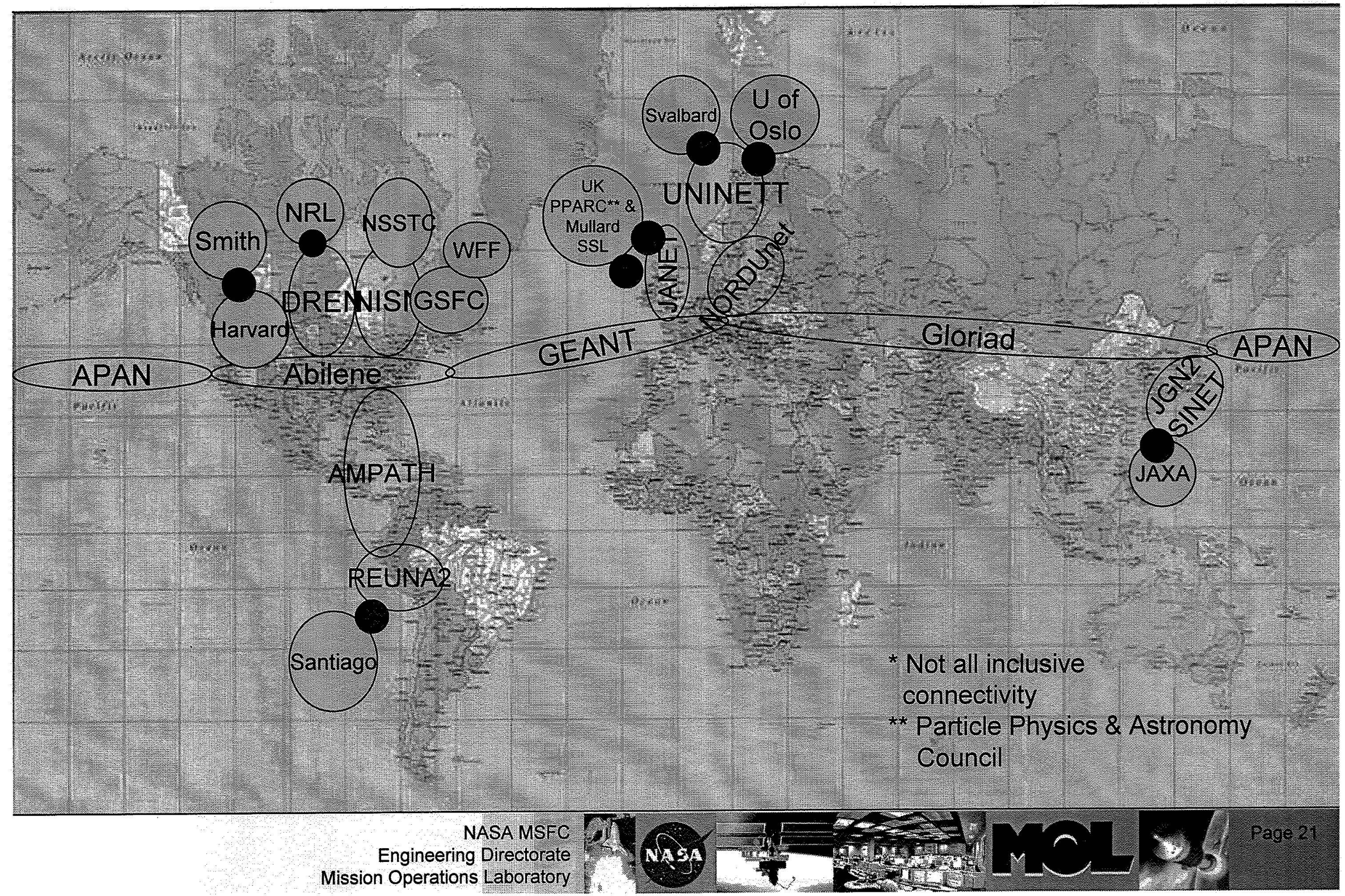




\section{Security}

- REN Security

- Security for user data is the responsibility of the user

- RENs do not divulge network security mechanisms anymore than does any other network 


\section{Future Technologies and Bandwidth Availability}

- Dense Wave Division Multiplexing

- How many lambdas to a fiber??

Light switching and routing

- Application selection

$\checkmark$ Fiber to the desktop 


\section{Conclusion}

- The performance of the Abilene network and generally of national and international RENs is more than adequate to support space based science operations for science conducted on manned and unmanned vehicles and satellites

- Meets or exceeds the NISN published performance specifications for mission ops

- 38ms worst case one way latency (for week of April 3)

- No packet loss

- 99.997\% availability in CY05 with no interruption of service

- Adequate bandwidth based on utilization stats and technology base

- Uses advanced networking technologies with plans looking to the future

- Their use can avoid significant networking cost in space-based science operations 